\title{
KLASIFIKASI KATEGORI BUKU PADA PERPUSTAKAAN TEKNIK INFORMATIKA UNIVERSITAS ISLAM LAMONGAN
}

\author{
Nurul Qomariyah' ${ }^{1)}$, Nur Nafi'iyah' ${ }^{2)}$, Ayu Ismi Hanifah ${ }^{3)}$ \\ ${ }^{1)}$ Mahasiswa Program Studi Teknik Informatika, Fakultas Teknik, Universitas Islam Lamongan \\ ${ }^{2,3)}$ Dosen Program Studi Teknik Informatika, Fakultas Teknik, Universitas Islam Lamongan \\ Jl. Veteran No. 53 A Lamongan \\ Telp. (0322) 324706 \\ E-mail: resdearestin@gmail.com ${ }^{1}$, mynaff26@gmail.com ${ }^{2}$, martinus.w.mahendra@gmail.com ${ }^{3}$
}

\begin{abstract}
The large number of library materials in the form of new book available in the library every year cause officer have difficulty in classification process book. Similarly, faced by librarian of Islamic University of Lamongan became the object of this research, determining the type or category of book at first the usual system. The process is made a lot of errors because it is based on the knowledge of officers from reading the title or the appropriate category so that makes it difficult for library users to find the materials needed. Application applied in the research is a data classification application that is done automatically using the application developed by Naive Bayes Classifier method with the application of client software web-based. Web-based server application function to input book by administrator and to classify data book based on the title. Based on the experience, and then in this research built an Classification Of Books Category At The Islamic University Of Lamongan Engineering Library.
\end{abstract}

Keywords: Library, Classification, Nä̈ve Bayes Classifie

\section{PENDAHULUAN}

Setiap mata kuliah memiliki silabus perkuliahan yang berisi materi-materi mengenai mata kuliah tersebut. Silabus disusun berdasarkan buku-buku referensi utama dan referensi pendukung dari matakuliah tersebut. Ada beberapa buku yang sering dijadikan referensi bersama atas Beberapa matakuliah. Ada juga buku-buku yang dijadikan referensi tunggal suatu mata kuliah,tetapi bahasan materi mata kuliah yang bersangkutan tidak dibahas secara optimal dalam buku referensi tersebut.

Seringkali judul suatu buku dijadikan gambaran umum mengenai isi suatu buku, padahal isi dari buku tersebut dapat jadi menjelaskan hal yang lain. Daftar isi buku merupakan gambaran khusus dari isi suatu buku. Dari melihat daftar isi, dapat diketahui materi-materi apa saja yang dibahas dalam buku tersebut.

Data yang digunakan di sini adalah data perpustakaan. Perpustakaan merupakan tempat yang cukup sering dikunjungi baik hanya sekedar membaca ataupun untuk mencari referensi. Fasilitas dan kenyamanan bagi pengunjung merupakan hal yang senantiasa perlu ditingkatkan diantaranya mempermudah pengunjung dalam hal pencarian buku dengan memanfaatkan software yang ada sehingga dapat membantu para pengunjung lebih cepat mengetahui daftar buku serta tempat penyimpanan buku yang ada pada perpustakaan tersebut dengan keakuratan pengklasifikasian dokumen yang baik. Untuk itu dibutuhkan metode Nä̈ve Bayes Classfier untuk klasifikasi dokumen (di sini dokumen berupa data buku yang ada di perpustakaan) yang akan diterapkan dalam membangun perangkat lunak pencarian pada Aplikasi Perpustakaan. Fungsinya untuk mempercepat proses pencarian data buku pada

159|P a g e
Aplikasi Perpustakaan sehingga membantu meningkatkan pelayanan pada perpustakaan.

Adapun tujuan pada penelitian ini adalah sebagai berikut: Mengimplementasikan metode Nä̈ve Bayes untuk mengklasifikasi koleksi buku perpustakaan berdasarkan kategori buku yang tersedia di perpustakaan Universitas Islam Lamongan, sehingga mempermudah pengelola perpustakaan dalam mengatur, mengelola, menyimpan, dan mengumpulkan koleksi buku serta mempermudah pengunjung dalam mencari buku yang diperlukan. Menganalisis tingkat keakuratan penggunaan metode Nä̈ve Bayes dalam mengklasifikasi buku berdasarkan kategori buku di Perpustakaan Teknik Universitas Islam Lamongan.

\section{METODE PENELITIAN}

Pengumpulan DataData yang digunakan pada penelitian ini berupa data sinopsis buku yang didapat dari perpustakaan Teknik Universitas Islam Lamongan. Sinopsis buku yang digunakan hanya buku yang berhubungan dengan fakultas teknik Teknik Universitas Islam Lamongan berdasarkan kategori yang telah ditentukan yaitu komputer dan informasi, ilmu komputer, pengetahuan umum, sistem, proses data, pemrograman program \& data , dan metode komputer.

Text mining merupakan variasi dari data mining yang berusaha menemukan pola yang menarik dari sekumpulan data tekstual yang berjumlah besar.

Analisis kebutuhan fungsional dilakukan untuk memberikan gambaran mengenai permasalahan dan prosedur yang sedang berjalan saat ini Analisis kebutuhan non fungsional dilakukan untuk mengetahui spesifikasi kebutuhan untuk sistem. Spesifikasi kebutuhan melibatkan analisis perangkat 
keras/hardware, analisis perangkat lunak/software, analisis pengguna/user.

Pada UML diagram ini menjelaskan tentang desain arsitektur yang dibuat dalam perancangan program yakni Diagram Korteks dan Data Flow Diagram.

Model yang dibuat berdasarkan anggapan bahwa dunia nyata terdiri dari koleksi obyek-obyek dasar yang dinamakan entitas (entity) serta hubungan (relationship) antara entitas-entitas yang ada pada sistem.Biasanya direpresentasikan dalam bentuk Entity Relationship Diagram.

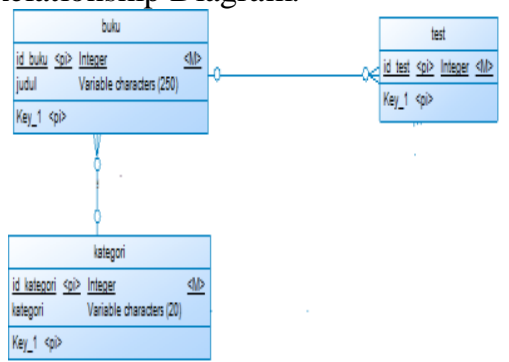

Gambar 1. CDM Kategori Klasifikasi Buku

Merupakan model yang menggunakan sejumlah tabel untuk menggambarkan data serta hubungan antara data-data tersebut. Setiap tabel mempunyai sejumlah kolom di mana setiap kolom memiliki nama yang unik.

Proses kerja CDM dan PDM pada program klasifikasi buku perpustakaan adalah sebagai berikut:

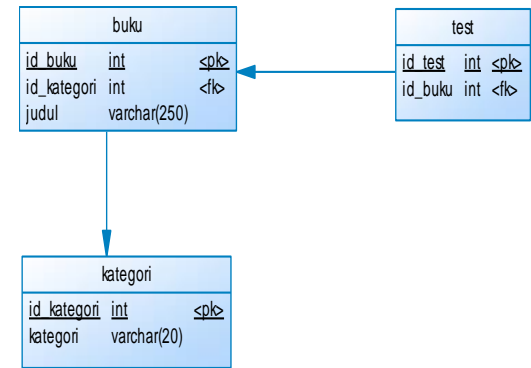

Gambar 2. PDM Kategori Klasifikasi Buku

Pada UML diagram ini menjelaskan tentang desain arsitektur yang dibuat dalam perancangan program yakni Diagram Korteks dan Data Flow Diagram. Diagram Konteks adalah suatu diagram alir tingkat tinggi yang menggambarkan seluruh jaringan, masukan, dan keluaran. Sistem yang dimaksud adalah untuk menggambarkan system yang sedang berjalan.

Secara uraian dapat dikatakan bahwa diagram konteks itu berisi siap yang memberkan data (inputan) ke system itu brisi siapa saja yang memberikan data (inputan) ke sistem, serta siapa data informasi itu diberikan melalui (sistem). (Saputra,2012:20) Pada diagram konteks ini merupakan gambaran secara umum tentang proses klasifikasi kategori buku, yang secara umum terdiri dari Admin sebagai pengirim data, sistem sebagai pengolah data yang akan disampaikan ke admin dan mengklasifikasikan buku menggunkan metode bayes
Naïve Bayes Classifier dan Mahasiswa menginput dan menghasilkan kesimpulan untuk jenis buku.

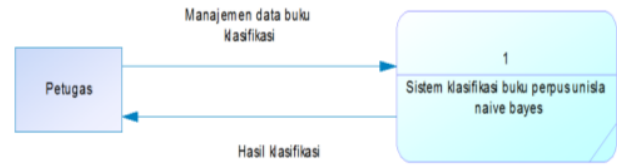

Gambar 3. Diagram Kontex Klasifikasi Kategori Buku

\section{Keterangan:}

Petugas perpustakan memasukkan data buku kedalam sistem untk diproes klasifikasi berdsarkan kategori buku. Sistem klasifikasi buku akan muncul untuk hasil kategori buku untuk dikategorikan petugas.

\section{PEMBAHASAN}

Implementasi sistem adalah langkah-langkah atau prosedur-prosedur yang dilakukan dalam menyelesaikan desain sistem yang telah disetujui, untuk menguji, menginstal dan memulai sistem baru atau sistem yang diperbaiki untuk menggantikan sistem yang lama. Implementasi yang telah sesuai harus di uji coba sehingga dapat diketahui kehandalan dari sistem yang ada telah sesuai dengan apa yang diinginkan.

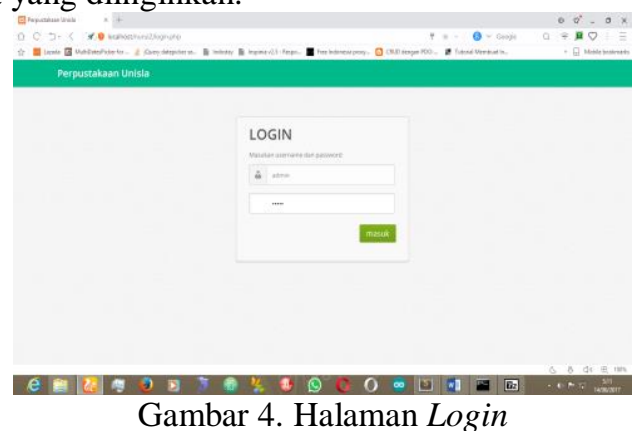

Setelah berhasil masuk halaman login selanjutnya dapat masuk e halaman home seperti gambar di bawah ini:

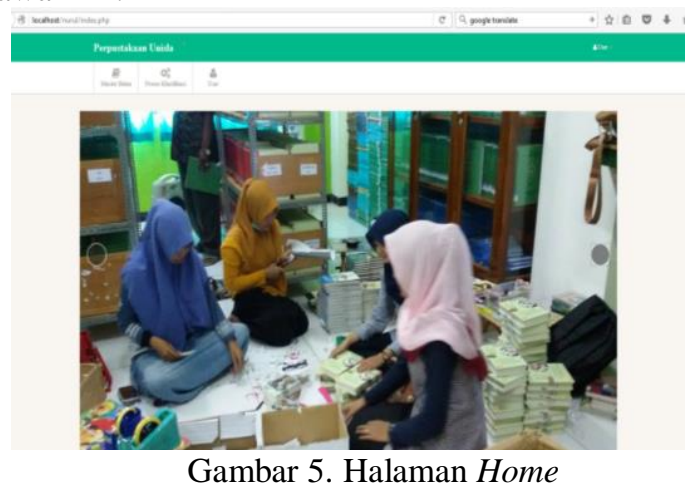

Setelah berhasil masuk halaman login pada halaman home selanjutnya dapat masuk ke halaman master buku seperti gambar di bawah ini. 


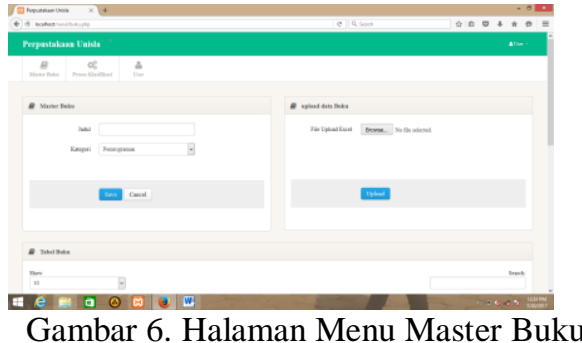

Pada menu master buku terdapat table judul buku yang akan dimasukkan kedalam databse dan kolom keterangan untuk menginputkan buku secara manual juga bias menginputkan data buku pada excel yang sudah disimpan.

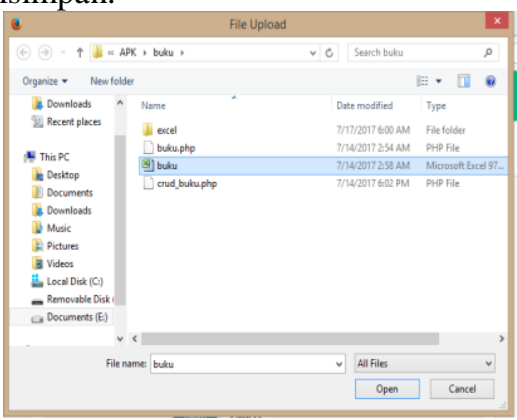

Gambar 7. Tempat Penyimanan Data Excel yang Tersimpan

Setelah berhasil menginputkan judul maka akan diproses kedalam proses klasifikasi seperti gambar di bawah ini.

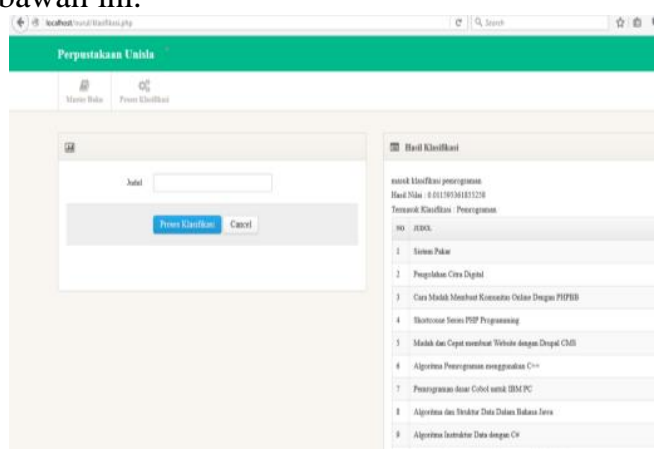

Gambar 8. Halaman Menu Master Buku

Pada menu Proses Klasifikasi terdapat inputan dengan memasukan Judul buku yang nantinya akan di olah yang menentukan klasifikasi kategori dan mengurutkan judul buku dengan berdasarkan perhitungan Metode Bayes. Pengujian dilakukan pada pencarian berdasarkan deskripsi, dengan menggunakan metoda Nä̈ve Bayes Classifier. Sehingga dapat di tentukan. Judul buku yang merupakan klasifikasi dari keyword yang di masukkan oleh user misalnya Internet". Berikut hasil pengujian dengan memasukkan kata "Internet" dalam kolom pencarian.

$$
\begin{aligned}
& \mathrm{P}(\mathrm{vn})=\frac{\llbracket \text { docs }_{j} \|}{\| \text { Contoh } \|} \quad \ldots \ldots \ldots \ldots \ldots \\
& P(w k \mid v n)=\frac{n k+1}{n+\mid \text { kosakata } \mid} \ldots \ldots \ldots .
\end{aligned}
$$

Tabel Rumus 1. Perhitungan Nä̈ve Bayes Classifier
Keterangan:

- $\mathrm{P}(\mathrm{vn})$ : Probabilitas setiap dokumen terhadap sekumpulan dokumen.

- $\quad \mathrm{P}(\mathrm{wk}|\mathrm{vn}|) \quad$ : probabilitas kemunculan kata wk pada suatu dokumen dengan class vj.

- $\mid$ docs $\mid$ : frekuensi dokumen pada setiap kategori.

- $\mid$ Contoh $\mid$ : jumlah dokumen yang ada.

- $\mathrm{Nk} \quad$ : frekuensi kata ke - k pada setiap kategori.

- Kosakata : jumlah kata pada dokumen test.

Pada persamaan (2) terdapat suatu penambahan 1 pada pembilang, hal tersebut dilakukan untuk mengantisipasi jika tedapat suatu kata pada dokumen uji yang tidak ada pada setiap dokumen data mining. Cara kerja Bayesian Classification:

1. Misalkan ada satu set sampel $S=\{S 1, S 2, \ldots ., S m\}$ (m adalah total sampel) di mana setiap sampel $\mathrm{Si}$ diwakili vektor $n$ dimensi $\{\mathrm{X} 1, \mathrm{X} 2, \ldots ., \mathrm{Xn}\}$. Nilai $\mathrm{Xi}$ sesuai dengan atribut $\mathrm{A} 1, \mathrm{~A} 2, \ldots .$. An masingmasing. Juga ada kelas $\mathrm{k} \mathrm{C} 1, \mathrm{C} 2, \ldots ., \mathrm{Ck}$, dan setiap sampel milik salah satu kelas. Data tambahan sampel X tidak diketahui kelasnya. Untuk memprediksi kelas dari sampel baru tersebut menggunakan probabilitas kondisional $\mathrm{P}(\mathrm{Ci} \mid \mathrm{X})$, di mana i adalah kelas-kelas yang ada. Probabilitas ini dihitung dengan menggunakan Teorema Bayes:

$\mathrm{P}(\mathrm{Ci} \mid x)=\frac{P(X \mid C i) \cdot P(C i)}{P(X)}$

2. $\mathrm{P}(\mathrm{X})$ adalah konstan dari semua kelas, hanya $\mathrm{P}(\mathrm{X} \mid \mathrm{Ci}) . \mathrm{P}(\mathrm{Ci})$ yang perlu dimaksimalkan.Dihitung prior probability kelas. Karena perhitungan dari $\mathrm{P}(\mathrm{X} \mid \mathrm{Ci})$ sangat kompleks, terutama untuk set data yang besar, asumsi Naive dari conditional independence antara atribut dibuat. Menggunakan asumsi kita dapat mengekpresikan $\mathrm{P}(\mathrm{X} \mid \mathrm{Ci})$ sebagai produk:

$\mathrm{P}(\mathrm{X} \mid C i)=\prod_{\mathrm{t}=1}^{\mathrm{n}} \mathrm{P}\left(\mathrm{X}_{\mathrm{t}} \mid \mathrm{C}_{\mathrm{t}}\right)$

di mana Xt adalah nilai-nilai untuk atribut dalam sampel X. Probabilitas $\mathrm{P}(\mathrm{Xt} \mid \mathrm{Ci})$ dapat diperkirakan dari training set data. Untuk mengklasifikasikan contoh $\mathrm{X}, \mathrm{P}(\mathrm{X} \mid \mathrm{Ci}) . \mathrm{P}(\mathrm{Ci})$ dievaluasi tiap kelas $\mathrm{Ci}$. Data contoh $\mathrm{X}$ untuk kelas $\mathrm{Ci}$ jika dan hanya jika:

3. Bayesian Classification memiliki akurasi dan kecepatan yang tinggi saat diaplikasikan ke dalam database dengan data yang besar. Metode ini memiliki tingkat kesalahan minimal dibandingkan dengan semua classifier lain yang dikembangkan dalam Data Mining. Tetapi,bagaimanapun juga tidak ada metode yang dapat memprediksi secara tepat sempurna.

Tabel 1. Data buku dalam databse

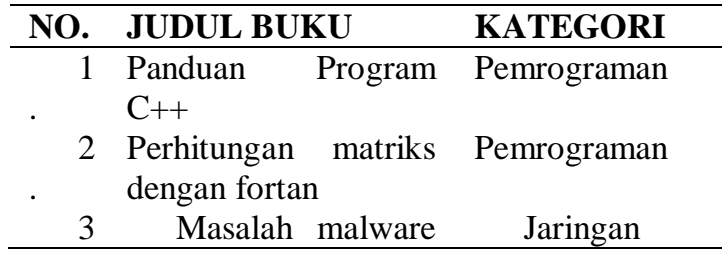




\begin{tabular}{|c|c|c|c|}
\hline . & & dan penanganannya & \\
\hline . & 4 & $\begin{array}{l}\text { Ancaman internet } \\
\text { hacking dan trik } \\
\text { menanganinya }\end{array}$ & Jaringan \\
\hline . & 5 & $\begin{array}{l}\text { Basic data dalam } \\
\text { tujuan konseptual }\end{array}$ & Database \\
\hline . & 6 & $\begin{array}{c}\text { Belajar database } \\
\text { menggunkaan MySql }\end{array}$ & Database \\
\hline
\end{tabular}

Tabel 2. Judul buku yang diproses

\begin{tabular}{lrl}
\hline \multicolumn{2}{c}{ JUDUL BUKU } & KATEGORI \\
\hline \multicolumn{1}{c}{ Ancaman } & internet & $?$ \\
$\begin{array}{l}\text { hacking dan } \\
\text { menanganinya }\end{array}$ & trik & \\
\hline
\end{tabular}

\section{Jawab:}

Tahap 1 mengjitung jumlah class / label

$\mathrm{P}(\mathrm{y}=$ PEMROGRAMAN $)=2 / 6$ 'jumlah data' PEMROGRAMAN pada komom ' KATEGORI' dibagi jumla data.

$\mathrm{P}(\mathrm{y}=\mathrm{JARINGAN})=2 / 6$ "jumlah data 'JARINGAN" pada komom "KATEGORI” dibagi jumlah data.

$\mathrm{P}(\mathrm{y}=$ DATABASE $)=2 / 6$ "jumlah data "DATABASE" pada komom "KATEGORI" dibagi jumlah data. Tahap 2 menghitung jumlah kata yang sama dengan inputan "Internet"

Tabel 3. Hasil Perhitungan Jumlah Kata Inputan

\begin{tabular}{|c|c|}
\hline INPUT JUDUL TEST & PEMROGRAMAN \\
\hline Ancaman internet & Jumlah $=0$ \\
\hline dan trik & $0+1$ \\
\hline menanganinya & $\overline{2+3}=\frac{7}{5}$ \\
\hline
\end{tabular}

Tahap 3 Kalikan semua hasil variabel. Hasil akhir perkalian $\mathrm{P}(\mathrm{H})$. $\mathrm{P}(\mathrm{E} \mid \mathrm{H})$

Tabel 4. Hasil Perhitungan Variabel

\begin{tabular}{llll}
\hline INPUT & PEMRO & JARING & DATAB \\
JUDUL & GRAM & AN & ASE \\
TEST & AN & & \\
\hline $\begin{array}{l}\text { Ancaman } \\
\text { internet }\end{array}$ & $\frac{2}{6} \times \frac{1}{5}=0.06$ & $\frac{2}{6} \times \frac{2}{5}=0.133 \frac{2}{6} \times \frac{1}{5}=0.06$ \\
hacking dan & & \\
trik \\
menanganin
\end{tabular}

Tahap 4 bandingkan hasil class Jaringan, Pemrograman,Database. Karena hasil (P|JARINGAN) lebih besar dari (P|PEMROGRAMAN) , (P|DATABSE) maka keputusan kategori kalsifikasinya adalah "JARINGAN".

Tabel 5. Hasil Klasifikasi Kategori Buku

\begin{tabular}{|c|c|}
\hline JUDUL BUKU & KATEGORI \\
\hline $\begin{array}{l}\text { Ancaman internet hacking } \\
\text { dan trik menanganinya }\end{array}$ & JARINGAN \\
\hline
\end{tabular}

Tahap uji coba aplikasi dilakukan untuk mengetahui letak kesalahan-kesalahan pada source code yang telah dibuat. Selain itu tahap uji coba sistem dilakukan untuk mengetahui hasil kesesuaian data perhitngan manual dengan hasil perhitungan pada sistem. Untuk penjelasan yang lebih spesifik tentang hasil uji coba aplikasi akan dijelaskan pada hasil berikut.

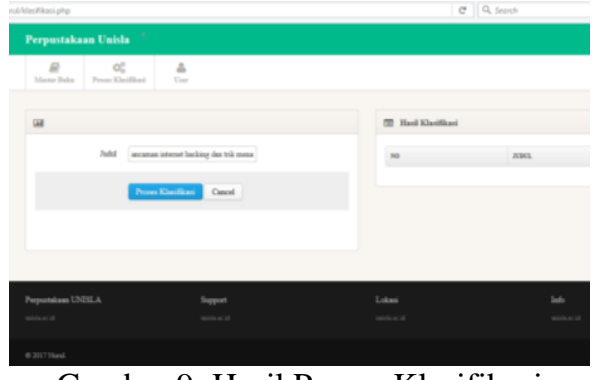

Gambar 9. Hasil Proses Klasifikasi

Menurut hasil pada aplikasi menunjukkan bahwa perhitungan pada sistem dengan perhitungan manual yang telah peneliti lakukan hasilnya sama, sehingga dapat dikatakan bahwa uji sistem aplikasi telah berhasil.

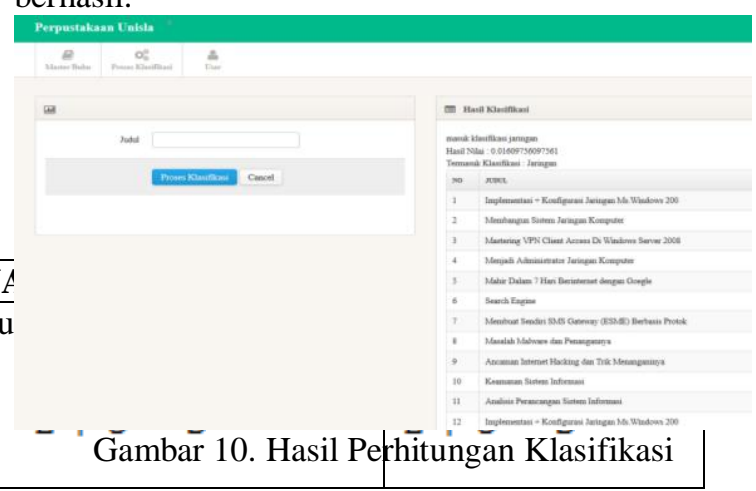

\section{KESIMPULAN}

Berdasarkan uraian tersebut di atas, mengenai perancangan aplikasi Klasifikasi Kategori Buku pada Perpustakaan Teknik Informatika UNISLA maka dapat di ambil kesimpulan sebagai berikut: Perancangan sistem informasi perpustakaan telah berhasil dilakukan dengan baik dan dapat memudahkan admin dalam pengolahan pengelompokan buku berdasarkan kategori buku. Dan mudah diakses para petugas perpustakaan menggunkan web dekstop.

\section{REFERENSI}

[1] Sodibyo ,Noerhayati: 1995) Pengolalan Perpustakaan. Bandung:IKAP

[2] Astuti ,Fajar: 2013.Data Mining .Surabaya: Universitas 17 Agustus ,CV.Andi

[3] Kusrini:2009. Algoritma Mining.Yogyakarta: STMIK AMIKOM

[4] Kurniawan,Hendra:2002.Aplikasi Penjualan dengan Program Java Netbeans,Xammp dan iReport. Surabaya:Kompas ramedia

[5] Raharjo,Budi: 2016.Modul Pemrograman Web.Bandung: Modula 
